\title{
LEITURA DE LINDANOR CELINA: CAMINHOS PARA A COMPREENSÃO DO TEXTO LITERÁRIO
}

\author{
Abílio Cavalcante Dantas Neto ${ }^{1}$ \\ Gunter Karl Pressler ${ }^{2}$
}

\begin{abstract}
RESUMO
O texto presente inicia a investigação sobre as possibilidades de leitura da obra de Lindanor Celina. A abordagem se dá a partir do conceito de mundo de relevância do estudioso Karlheinz Stierle e as reflexões sobre a existência do campo da Literatura da Amazônia trabalhadas pela pesquisadora Camila do Valle.
\end{abstract}

Palavras-chave: Teoria da Recepção. Amazônia. Regionalismo.

\begin{abstract}
The present text begins the investigation into the possibilities of reading the work of Lindanor Celina. The approach is based on the concept world of relevance of the scholar Karlheinz Stierle and the reflections on the existence of the field of Literature of the Amazon worked by the researcher Camila do Valle.
\end{abstract}

Keywords: Reception theory. Amazon. Regionalism.

Recebido em: 10/08/2017

Aprovado em: 04/09/2017

\section{DE ONDE VEM A AUTORA?}

Lindanor Celina Coelho Casha é uma escritora. Essa é uma afirmação incontestável. Para comprovar sua veracidade, basta que se consulte a sua obra, que é formado por 15 criações literárias (PENHA, 2008), sendo elas romances, livros de crônicas, livros de memórias, livro de poemas e peça de teatro. A autora foi também pesquisadora e professora na Universidade de Lille III, na França, onde ministrou disciplinas sobre literatura e cultura brasileira e desenvolveu uma tese de doutoramento sobre o conto na obra de Mário de Andrade, intitulada "Quelques aspectes du conte chez Mário de Andrade”.

No entanto, embora sua produção escrita seja um fato em qualquer lugar do mundo, em textos sobre seu trabalho e matérias jornalísticas há, frequentemente, a presença de dois adjetivos classificatórios de sua trajetória artística e intelectual que induzem previamente o leitor a determinados caminhos de interpretação. São eles as palavras: paraense e amazônida.

\footnotetext{
${ }^{1}$ Mestrando do Programa de Pós-graduação em Linguagens e Saberes da Amazônia (PPLSA) da Universidade Federal do Pará (UFPA). E-mail: dantasablio3@ gmail.com

${ }^{2}$ Professor de Teoria Literária na Universidade Federal do Pará/UFPA. Programa de Pós-Graduação em Letras (PPGL), Programa de Pós-Graduação em Linguagens e Saberes da Amazônia (PPLSA). E-mail: gupre@ufpa.br.
} 
Lindanor Celina passa, então, a ser uma escritora passível a ser limitada a um determinado campo interpretativo.

A criadora dos livros "Menina que vem de Itaiara", "Símbolo", "Contracanto", “Estradas do Tempo-foi”, "Breve Sempre”, "Pranto pra Dalcídio Jurandir", "Para além dos Anjos", "Afonso Contínuo, Santo de Altar", "A viajante e seus espantos", "Eram seis assinalados", entre outros, nasceu, de fato, no estado do Pará, no dia 21 de outubro de 1917. Mais especificamente, no município de Castanhal, e faleceu em 4 de março de 2013. Ainda na infância mudou-se para a cidade de Bragança, localizada no nordeste paraense, e depois morou em locais como Belém, São Luís do Maranhão e, por fim, Paris. A pessoa de Lindanor Celina, sem dúvidas, tendo em vista o território onde se deu seu nascimento, é brasileira, da região amazônica, e paraense. O que buscamos questionar e refletir aqui é o papel que a territorialidade da biografia de uma autora ou um autor cumpre no modo como sua obra é recebida, analisada e difundida, e como esta, pode estar presente, de forma explícita ou não, na obra.

\section{CRÍTICA}

No prefácio do romance "Eram seis assinalados", o crítico Fábio Lucas afirma, logo no início de seu texto, que a autora reflete em sua obra "o conflitivo ambiente de seu Estado natal, o Pará" (CELINA, 1994, p.7). Para ele, em seu preâmbulo, a análise das relações sociais que ali se dão são o principal tema e mérito da obra. E sobre a Amazônia, o crítico entende que "A interação homem-natureza ali é de tal forma exuberante que os escritores não escapam do estigma de retratar os conflitos humanos perante o mistério das condições ambientais, sempre determinantes.” (Ibid.) Lindanor seria diferente por não agir dessa maneira.

A citação acima exige uma percepção metódica para a compreensão de seu sentido. $\mathrm{O}$ autor afirma, como justificativa para a possível predominância da produção literária que prioriza como temática, segundo ele, as condições ambientais da região, que a relação, na Amazônia, entre homem e natureza é exuberante e esta última torna-se, portanto, determinante nas obras dos escritores. Nenhum argumento é apresentado para explicar a citada exuberância. Nenhum autor ou obra é referida, inclusive. Podemos entender que, implicitamente, ele refere-se à dimensão da floresta amazônica e sua influência sobre os indivíduos? Acreditamos que sim. Identificamos aqui o predomínio do senso comum. No 
entanto, a questão histórica do território, e não sua natureza apenas física, é que determina, para ele, a rigidez das relações sociais abordadas por Lindanor Celina. Como afirma:

\begin{abstract}
E mais: se o espaço geográfico é rígido às motivações volitivas das personagens, mais inflexível se mostra a estrutura social que a herança histórica impôs à região. $\mathrm{O}$ patrimonialismo fundiário deitou raízes tão profundas na Amazônia que a conduta humana ali se rege por estilos comportamentais que reproduzem e aprofundam o poder dominante (CELINA, 1994, p.7).
\end{abstract}

O texto do prefácio declara ainda que o romance é um discurso sobre a liberdade e também o sobre o controle social que é posto contra essa mesma liberdade. No entanto, esta afirmação é seguida de mais uma volta ao papel central da região como um trunfo da narrativa. Ao que parece, para Fábio Lucas, todos os pontos positivos do romance apontam para o modo como a autora escreve sobre sua região. "O leitor haverá de deliciar-se com os coloquialismos tão bem utilizados pela romancista. E se encantará com imagens, símiles e metáforas que povoam a narrativa, de grande referencialidade regional" (CELINA, 1994, p.9). E reitera nos últimos parágrafos que é "Bastante rico este romance de Lindanor Celina. Traz, mais uma vez, uma contribuição valiosa à literatura regional da Amazônia" (CELINA, 1994, p.10).

\footnotetext{
$\mathrm{Na}$ verdade, Eram Seis Assinalados relata o drama de uma queda. O microcosmo familiar gira em torno de Irene. Ao todo, seis pessoas. A seguir, entremostra os caminhos da redenção. O rendilhado da prosa de Lindanor Celina adiciona ao relato o poder da consciência verbal de sua região (CELINA, 1994, p.10).
}

O escritor Antônio Olinto, autor da apresentação do romance "Breve Sempre", intitulada "Uma História que flui" (CELINA, 1973, p.3), a exemplo de Fábio Lucas, trata também a questão da territorialidade como um elemento importante a ser considerado pela crítica literária. No trecho em que aborda o contexto literário da época, ele afirma que "no meio de uma espantosa diversidade temática e estilística, há nesses romances uma unidade brasileira. Claro que, no caso, é uma unidade nacional de língua e de espírito, com uma dissimilitude que vem da continentalidade do País" (Ibid. p.4).

Embora Olinto diga, mais adiante, que a verdade unitária encontrada nas obras vencedoras de prêmios nacionais, como o Prêmio Nacional Walmap, seja uma "verdade da ficção", ele não abre mão de citar o local de nascimento dos autores. É seguindo esta linha que ele classifica o livro de Lindanor Celina. Pelo fato da narrativa ser ambientada em Paris e sua autora ser amazônida, ele escreve: "Breve Sempre não é romance da Amazônia. E, contudo, não deixa de o ser. O que Lindanor Celina conta nele é a história de uma brasileira em Paris.” (CELINA, 1973, p.4). Para sustentar sua escolha, ele argumenta: 
Paris, vista por Lindanor Celina, aparece de modo diferente do que era costume haver em romances mais antigos. Sua Paris é a de agora, do começo da década de 70. E é também uma Paris brasileira, onde se fala português quase o tempo todo e onde uma pessoa não se sente muito afastada de Belém, Brasília ou Rio. (CELINA, 1973, p.5)

A área jornalística é também farta em textos que associam a vida e a obra de Lindanor à sua terra natal ou a sua saída dela. Constata-se isto pelo título de algumas matérias, como "Bragantina, amiga de Sartre e amante do Pará", publicada em 20 de julho de 1980, no jornal "O Estado do Pará"; "A literatura do Pará chega às universidades da Europa”, veiculada em 7 de julho de 1985, em "O Liberal"; "Senhora que vem de Paris", publicada em 29 de fevereiro de 1992, em "O Liberal"; "Letras do Norte: Lindanor Celina", veiculada também em "O Liberal", em 23 de fevereiro de 2009 e "Nossa embaixadora em Paris", publicada em 20 de agosto de 1990 no jornal "A Província do Pará".

A fim de investigarmos a questão da região amazônica como uma possível chave interpretativa da obra de Lindanor Celina, nos cabe perguntar, portanto: é possível afirmarmos a existência de uma Literatura da Amazônia? O que é a cultura amazônica dentro da obra de Lindanor Celina?

\section{A INDEFINIÇÃO DO CAMPO}

A pesquisadora Camila do Valle, no artigo "Literatura da Amazônia - dificuldades do surgimento e classificação de um campo", relata a experiência de investigação do tema a partir da criação da disciplina "Literatura da Amazônia", que foi ofertada à Universidade Federal do Pará no ano de 2009. Segundo a autora, a tentativa era de descrever a dimensão do campo, sem a pretensão de esgotar a temática.

A partir deste objetivo, foram divididas três partes para análise na criação da disciplina: a literatura dos viajantes que descreviam a região em suas expedições, a produção literária de romances, poemas e contos de pessoas da Amazônia ou que nela viveram e, por fim, os variados discursos da memória, que podem ser também classificados como "literatura oral" ou patrimônio intangível.

Uma das dificuldades relatadas foi a de trabalhar o conteúdo literário a partir de uma abordagem que não impusesse a dicotomia universal e regional como reafirmações do pensamento etnocêntrico europeu que inferioriza o segundo tipo e torna universal, ou comum, 
apenas aquilo que interessa à camada do poder social estabelecido. Neste ponto, Camila cita o estudioso Casanova, que afirma que o

\footnotetext{
universal é de certa forma uma das invenções mais diabólicas do centro: em nome de uma negação da estrutura antagonista e hierárquica do mundo, sob o pretexto de igualdade de todos em literatura, os detentores do monopólio do universal convocam a humanidade inteira a se dobrar a sua lei. $\mathrm{O}$ universal é o que declaram adquirido e acessível a todos, contanto que se pareça com eles. (CASANOVA, 2002, p. 194).
}

Outro ponto problemático é a definição de amazônico como algo que só é passível de ser encontrado neste território. A autora propõe, portanto, que se classifique, como método, as diferenças e as particularidades textuais que não podem ser reduzidas a normas. É proposto, assim, que se passe a repensar aqui o significado da palavra "cosmopolita", a fim de que não se caia na oposição entre regional e o universal, "como se somente a fixa dualidade pairasse sobre as possibilidades de organização da imaginação humana" (VALLE, Camila. Plural Pluriel Revue des cultures de langue portugaise, número 9).

A definição de literatura amazônica que não compreende a complexidade da formação da região, posto que esta se dá sem binarismos claros, demonstra e difunde a falta de informação existente sobre a região e serve ao discurso do universal enquanto comum e “acessível”, enquanto o oposto seria exótico e de acesso limitado.

\section{APONTAMENTOS}

Para que vislumbremos caminhos para a análise da obra de Lindanor Celina, tendo em vista a centralidade da questão amazônica em sua fortuna crítica, recorremos aos estudos da recepção literária do autor Karlheinz Stierle, que trabalha com o conceito de mundo de relevância. Vejamos se suas proposições podem ajudar-nos.

De acordo com o autor Gunter Karl Pressler, no texto "A Recepção de Obras Literárias e Críticas: A Questão da Experiência Estética (Ato da Leitura) e do Efeito (Estrutura Narrativa e Discursiva)", Stierle trabalha com a ideia de que o acontecimento, dentro de uma obra literária, seja ela na narrativa ficcional ou pragmática, é sempre uma pressuposição. Isto significa dizer que ele não existe enquanto uma verdade, um dado puro a ser alcançado.

Pelo contrário: o que importa é um conjunto de elementos organizados dentro da narrativa. Conjunto este que é chamado pelo teórico, no caso da ficção, de um ajuntamento de concepções constitutivo-ficcionais que vai dar origem ao chamado mundo de relevância, enquanto que na narrativa de ficção, o que busca-se alcançar é a relevância do acontecimento. 
Ao centrarmos nosso senso crítico para a presença de uma cultura ou ethos amazônico na obra de Lindanor Celina é necessário, além de aprofundar o debate introduzido no tópico anterior, compreendermos quais são os elementos utilizados pela autora na constituição de suas narrativas que constroem um mundo de relevância no qual é possível identificarmos associações à vida na região amazônica brasileira.

O romance "Eram seis assinalados", por exemplo, possui passagens que utilizam a dimensão simbólica dos rios, paisagem comum na Amazônia, como elemento significativo para a história narrada.

Irene, Irene, como hoje lhe parece imensa e estranha a cidade à beira daquele rio tão seu amigo, nos tempos da sua pureza. Agora o rio só passava, corria, descuidado, fazendo ouvidos moucos. O rio era apenas uma testemunha. Um dia pensou nele se afogar? Não, não. Pesar dos conselhos que deram, brandamente apontaram o rio, olha, é fácil, facílimo, eu, fosse tu... (CELINA, 1994, p.14)

Da mesma maneira, a constituição de casas, mais especificamente o espaço dos quintais, é utilizada como imagem poética e narrativa no romance "Estradas do Tempo-foi", no momento em que a personagem Irene recorda de sua terra natal, a cidade de Itaiara.

De tardezinha. Hora ruim escolheu, hora das melancolias. O velho quintal já se enchia de sombras, e ela foi dizendo adeus a cada coisa, ao trapézio, às mangueiras, à casa da lenha, à jaqueira, já em silhueta recortada contra o céu alto e lavado, onde se atreviam as primeiras estrelas. Estava justamente dizendo adeus ao coqueiro velho... (CELINA, 1971, p.21)

As relações sociais, tal como citadas no texto de Fábio Lucas, também são elementos passíveis de serem inclusos como importantes pontos para análise dos mundos de relevância criados por Lindanor. O gênero social, e como ele se apresenta e é constituído nas comunidades, é uma das temáticas presentes no romance "Menina que vem de Itaiara".

Papai vivia de andanças na Estrada de Ferro, negociando com peixe seco e camarão. Mamãe nunca saía de casa. Boa católica, nesses tempos, morria de vontade de ir à missa, uma novena, uma procissão. Éramos novatos na cidade, ela não conhecia ninguém a quem me confiar. (CELINA, 1963, p.7)

Conclui-se, portanto, que o conceito de Stierle nos sugere que é preciso encarar a obra literária "por dentro", a partir de suas próprias ferramentas. Nos cabe então, para um outro momento, a partir desta constatação, refletirmos de que maneira e com quais outros conceitos podemos adentrar a obra de Lindanor Celina a fim de compreendermos ou não a presença de alguma "amazônidade". 


\section{REFERÊNCIAS}

BARROS, Lídia Almeida. Curso Básico de Terminologia. São Paulo: Editora da Universidade de São Paulo, 2004.

BUTLER, Judith. Fundamentos contingentes: o feminismo e a questão do pósmodernismo. Cadernos Pagu, n. 11, p. 11-42, 1998.

CARVALHO, Flávia Medeiros de; FERREIRA, Alice Maria Araújo. Da sociolinguística à socioterminologia: definindo conceitos. Revista do Programa de Pós-Graduação em Estudo de Linguagens. Salvador. Número 5. 20 p, 2012.

CASANOVA, Pascale. República mundial das letras. Trad. Marina Appenzeller. São Paulo: Liberdade, 2002 apud VALLE, Camila do. Literatura da Amazônia- dificuldades do surgimento e classificação de um campo. Plura Plureil Revue des Cultures de langue portugaise- número 9: Amazoniez brésiliennes.

CELINA, Lindanor. Menina que vem de Itaiara. Rio de Janeiro: Conquista, 1963.

Estradas do Tempo-foi. Rio de Janeiro: JCM, 1971.

Eram seis assinalados. Belém: CEJUP, 1994.

Breve Sempre. Rio de Janeiro: Companhia Editora Americana, 1973.

Pranto por Dalcídio Jurandir. Belém: Gráfica Falangola Editora

LTDA, 1983.

FAULSTICH, Enilde. Socioterminologia: mais que um método de pesquisa, uma disciplina. Ciência da Informação - Vol. 24, número 3, 1995 - Artigos.

OLIVEIRA, Rosa Helena Souza de. A Estrutura Narrativa em Eram Seis Assinalados de Lindanor Celina. XII Congresso Internacional da ABRALI 18 a 22 de julho de 2011. Centro, Centros - Ética, Estética. Anais.

PENHA, Maria das Neves de Oliveira. A Cartografia de Irene na Trilogia de Lindanor Celina. 2008. 132f. Dissertação (mestrado em Estudos Literários) - Universidade Federal do Pará, Instituto de Letras e Comunicação (ILC), Belém, 2008.

PRESSLER, Gunter Karl. A Recepção de Obras Literárias e Críticas: A Questão da Experiência Estética (Ato da Leitura) e do Efeito (Estrutura Narrativa e Discursiva).

VALLE, Camila do. Literatura da Amazônia- dificuldades do surgimento e classificação de um campo. Plura Plureil Revue des Cultures de langue portugaise- número 9: Amazoniez brésiliennes.

ZOLIN, Lúcia Osana (Org.). Teoria Literária: abordagens históricas e tendências contemporâneas. 3. ed. rev. e ampl. Maringá: Eduem, 2009, p. 131-157. 